\title{
Clinical and radiological findings of a bilateral coronoid hyperplasia case
}

\author{
Kubra Torenek ${ }^{1}$, Suayip Burak Duman' ${ }^{1}$ Ibrahim Sevki Bayrakdar ${ }^{1}$, Ozkan Miloglu $^{1}$
}

Correspondence: Ibrahim Sevki Bayrakdar

Email: ibrahimsevkibayrakdar@gmail.com
'Department of Oral Diagnosis and Dentomaxillofacial Radiology, Faculty of Dentistry, Ataturk University, Erzurum, Turkiye

\section{ABSTRACT}

Coronoid hyperplasia $(\mathrm{CH})$ is an infrequent condition that can be defined as an abnormal bony elongation of histologically normal bone. Progressive and painless difficulty in opening the mouth is the main clinical finding of $\mathrm{CH}$. In this case report, the clinical and radiological findings for a 23-year-old male patient with bilateral $\mathrm{CH}$ are presented. When plain radiographies are not sufficient for diagnosis and evaluation of the $\mathrm{CH}$, cone-beam computed tomography can be used.

Key words: Cone-beam computed tomography, coronoid enlargement, coronoid hyperplasia

\section{INTRODUCTION}

Coronoid hyperplasia $(\mathrm{CH})$ is a rare condition that can be defined as an abnormal bony elongation of histologically normal bone. The main clinical finding of $\mathrm{CH}$ is progressive, painless difficulty in opening the mouth because of the impingement of the hyperplastic coronoid process with the temporal surface of the zygomatic bone or medial surface of the zygomatic $\operatorname{arch}^{[1,2]}$

The etiology of $\mathrm{CH}$ is not yet explained, and $\mathrm{CH}$ cases are not usually diagnosed easily due to the fact that the condition is often confused with other maladies. Therefore, a differential diagnosis should be made with radiography. Plain radiographies can be used to detect $\mathrm{CH}$, but these can be limited because of the fact that they provide only two-dimensional images. The cone beam systems can produce three-dimensional data with very low radiation doses at a time. At the same time, cone-beam computed tomography (CBCT) allows the realignment of two-dimensional images in coronal, sagittal, oblique, and various incline planes. Hence, CBCT can be a useful imaging method for this patient. ${ }^{[3,4]}$
The aim of this report was to present clinical and radiological findings of a bilateral $\mathrm{CH}$ case in the mandible and to show that CBCT can be used to detect mandibular $\mathrm{CH}$.

\section{CASE REPORT}

A 23-year-old male patient was referred to our dental clinic with a history of limitations in mouth opening. His medical anamnesis was not noteworthy. There were no musculoskeletal anomalies, congenital bone dysplasia, or trauma. Clinical examination did not reveal facial asymmetry, deviation, or pain. The interincisal mouth opening was measured as $18 \mathrm{~mm}$. Crepitation and clicking of temporomandibular joint (TMJ) were not seen. Pressure in the zygomatic region on maximal opening was detected. Hyperplasia of the coronoid process could be seen bilaterally on panoramic radiography and TMJ radiography, but that was not clear [Figures 1 and 2]. Therefore, CBCT was utilized for detailed diagnosis. Informed consent was received from the patient for the exposures. The patient had been scanned with CBCT (NewTom FP QR-DVT 9000, $110 \mathrm{kVp}, 15 \mathrm{~mA}, 36 \mathrm{~s}$ scan time, $5.4 \mathrm{~s}$ typical X-ray emission time, $17 \mathrm{~cm}$ diameter- $13 \mathrm{~cm}$

\footnotetext{
How to cite this article: Torenek K, Duman SB, Bayrakdar IS, Miloglu O. Clinical and radiological findings of a bilateral coronoid hyperplasia case. Eur J Dent 2015;9:149-52.

Copyright $\odot 2015$ Dental Investigations Society. DOI: $10.4103 / 1305-7456.149665$
} 
height scan volume, Verona, Italy) with an open and closed mouth to evaluate temporomandibular bone structure, condylar movement, and relationships among condyle, eminence, and zygomatic arch. The patient was placed in a horizontal position so that the Frankfort horizontal plane was perpendicular to the table, with the head within the circular gantry of the X-ray tube in order to obtain a consistent orientation of sagittal images. Raw data obtained from the CBCT generated volumetric and study data, including information on the mandible, using the NNT software program (QR-NNT version 2.21, Quantitative Radiology, Verona, Italy) for analysis. Images obtained from CBCT were examined in a multiplanar reconstruction mode. $\mathrm{CH}$ was observed on sagittal slices taken in the closed mouth [Figure 3]. Impingement of the bilateral $\mathrm{CH}$ with the medial aspects of the zygomatic arches was observed on the axial and coronal slices taken in the open mouth. There was no fusion between the coronoid processes and zygomatic arches on higher axial slices [Figures 4 and 5]. According to a three-dimensional view, $\mathrm{CH}$ was detected bilaterally in the mandible [Figures 6 and 7].

\section{DISCUSSION}

The etiology of $\mathrm{CH}$ is not clear, and various causes have been proposed. It could be related to developmental changes, bone pathologies (such as osteochondroma, exocytosis, and osteoma), increased temporal bone activity, genetic inheritance, endocrine stimulus, and trauma. ${ }^{[5-8]}$ In the literature, $\mathrm{CH}$ was first defined and named as Jacob disease by Jacob in 1899 as joint formation between an osteochondroma of the coronoid process and the zygomatic arches. ${ }^{[2]}$ In this present case, no causes were detected. There was no fusion between the coronoid process and the zygomatic arc on CBCT images. It may occur because of developmental changes. $\mathrm{CH}$ is thought to be a rare condition, and no epidemiological studies have been conducted, so incidence and prevalence numbers concerning $\mathrm{CH}$ are hard to find. The mean age at diagnosis was found to be 23-year-old. ${ }^{[9]} \mathrm{CH}$ can be seen as unilateral or bilateral with a bilateral: Unilateral ratio of 4.7:1. CH mostly affects males, with a male: Female ratio of 5:1. ${ }^{[2]}$ According to a review by Mulder et al. ${ }^{\left[{ }^{[9]}\right.} \mathrm{CH}$ is mostly seen in males, and the male-to-female ratio is 3.3:1, and bilateral $\mathrm{CH}$ is seen 4.1 times more frequently than the unilateral form. Unilateral $\mathrm{CH}$ is seen slightly more frequently in women, and bilateral $\mathrm{CH}$ is more frequently found in men. No significant association was found between sex and unilateral or bilateral $\mathrm{CH} .{ }^{[9]}$ Bilateral $\mathrm{CH}$ was

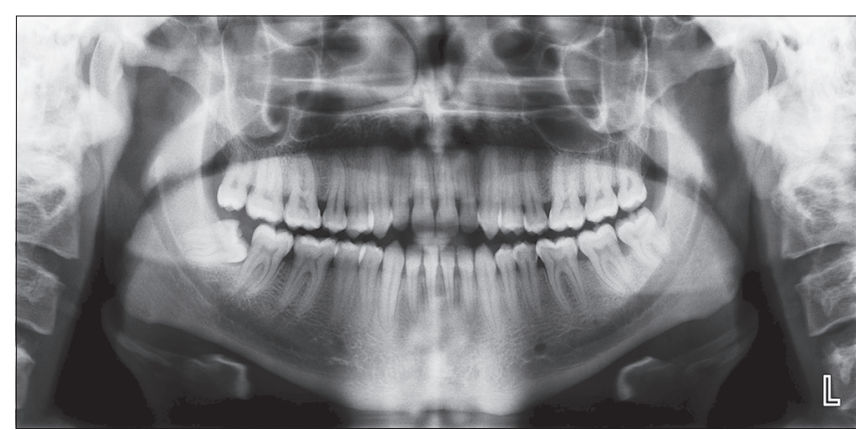

Figure 1: Ortopantomography shows the bilateral coronoid hyperplasia

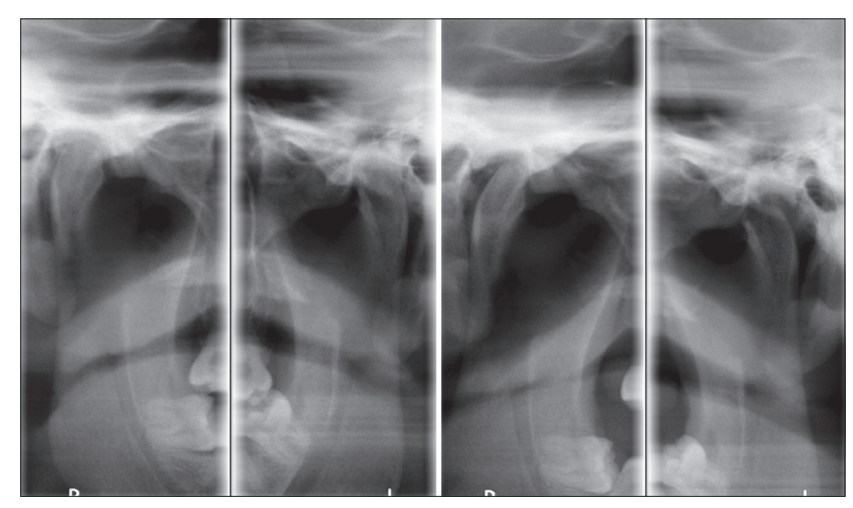

Figure 2: Transcranial radiograph of temporomandibular joint shows the bilateral coronoid hyperplasia

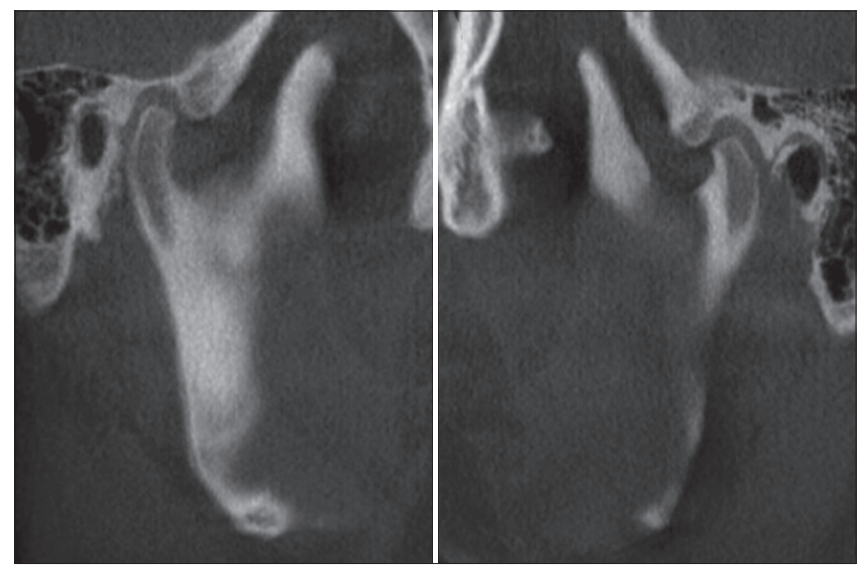

Figure 3: Bilateral coronoid hyperplasia is shown on sagittal slices in a closed mouth

diagnosed for the 23-year-old male patient in this present case.

The main complaint of patients with $\mathrm{CH}$ is slow, progressive, and painless limitations in mouth opening. Facial asymmetry and deviation are not seen on bilateral $\mathrm{CH}$, but facial asymmetry and deviation toward the affected side can be seen with the unilateral form. ${ }^{[10,11]}$ Crepitation and clicking of TMJ and the sensation of pain or pressure in the zygomatic region on maximal opening may be seen as less frequent symptoms. ${ }^{[7]}$ The mean interincisal opening was found 


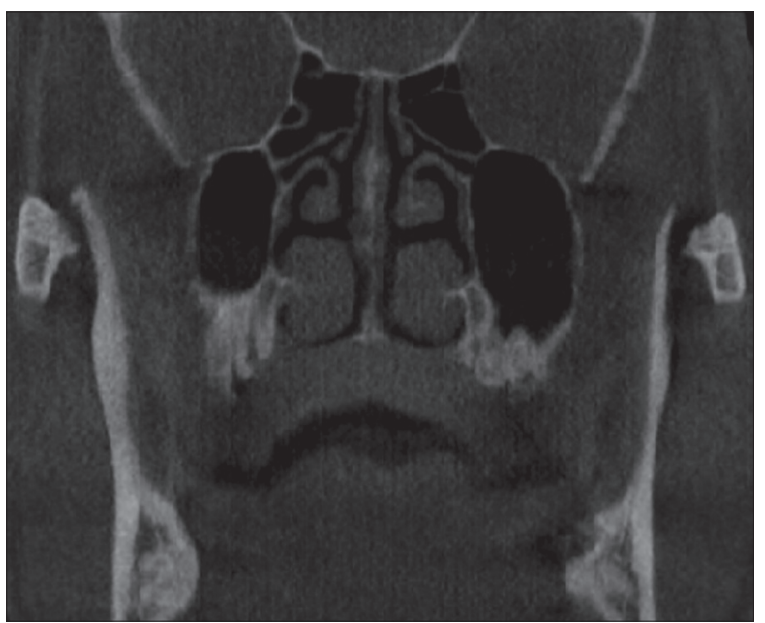

Figure 4: There was no fusion between the coronoid processes and zygomatic arches on the coronal slices with an open mouth
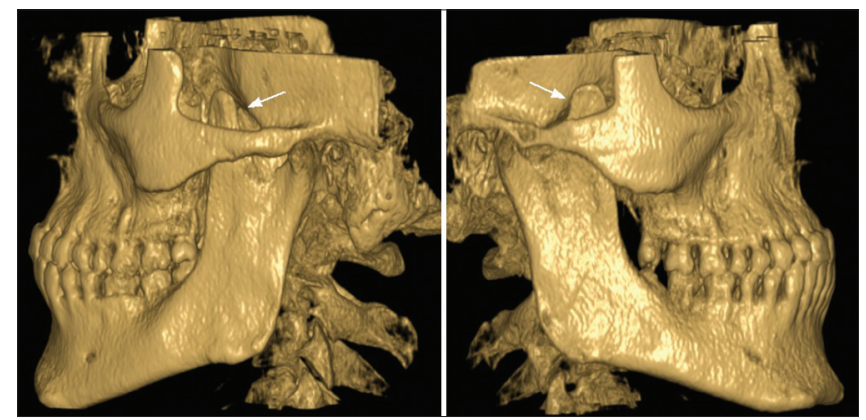

Figure 6: Three-dimensional images show bilateral coronoid hyperplasia in a closed mouth

as $15.3 \mathrm{~mm}$ in a study conducted by Tavassol et al. ${ }^{[12]}$ In this present case, facial asymmetry, deviation, crepitation, and clicking of TMJ were not seen in the examination. Maximum interincisal opening was found as $18 \mathrm{~mm}$, and pressure in the zygomatic region was seen on maximal opening.

The diagnosis of $\mathrm{CH}$ is confusing, and radiographic examination is essential. Plain radiographs are seen as an initial step for radiographic examination in the diagnosis of $\mathrm{CH}$. Orthopantomograph (OPT), transcranial radiograph of TMJ, occipitomental view, and cephalometric analysis can be used for the diagnosis of $\mathrm{CH}$. While the occipitomental view is useful in displaying the relationship between the coronoid process and zygoma, an OPT can clearly show the $\mathrm{CH}^{[8,13]}$ When a coronoid process height exceeds that of the condyle on the OPT, $\mathrm{CH}$ is suspected. In this present case, an OPT and transcranial radiograph of TMJ revealed the $\mathrm{CH}$, but not clearly. Additional imaging to confirm $\mathrm{CH}$ was needed. $\mathrm{CH}$ can be diagnosed by two-dimensional imaging, but this can be inadequate in some cases.

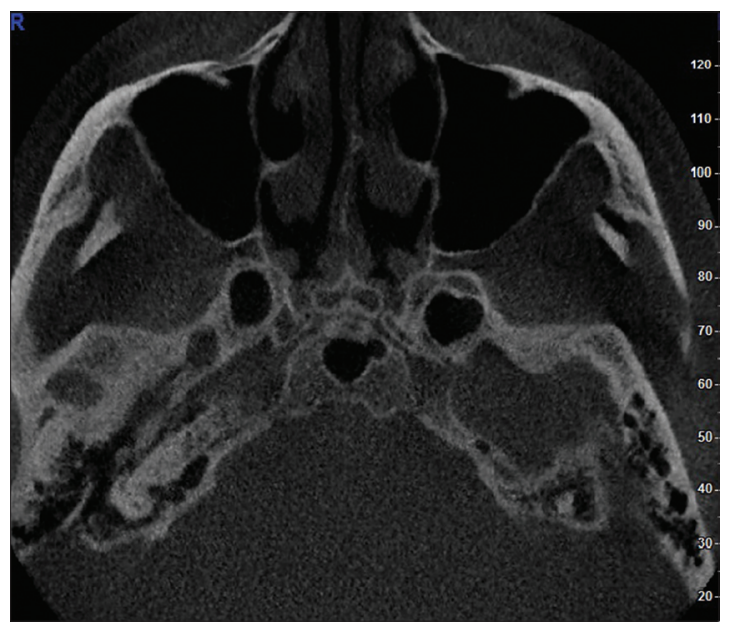

Figure 5: Bilateral coronoid hyperplasia is seen on higher axial slices in an open mouth

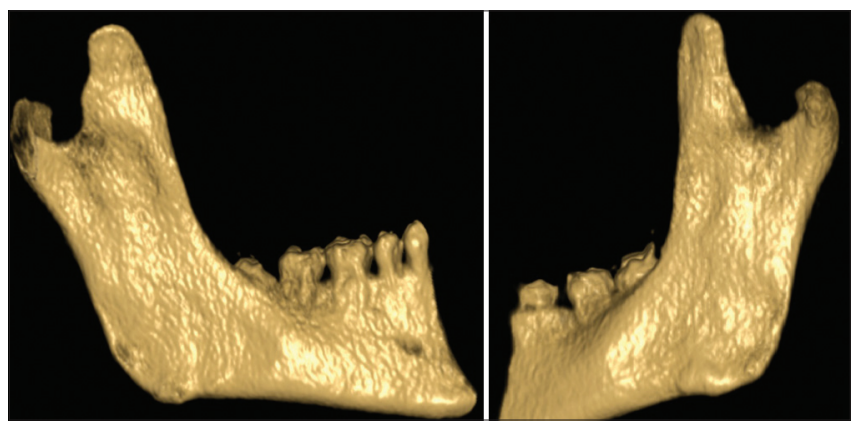

Figure 7: Three-dimensional images show bilateral coronoid hyperplasia on extracted mandible

Three-dimensional imaging includes data from all the two-dimensional images. $\mathrm{CH}$ has been previously evaluated with magnetic resonance imaging, $\mathrm{CT}$, and CBCT imaging, ${ }^{[14-16]}$ and three-dimensional CT can be used to evaluate the bone morphology in more detail. ${ }^{[3,4,16]}$ Three-dimensional CT imaging is essential in determining the correct diagnosis of $\mathrm{CH}$ and to specifically plan for surgery. CBCT has a low radiation dose, short imaging time, and better image resolution in comparison with $\mathrm{CT}$. In the present case, $\mathrm{CH}$ was detected with three-dimensional CBCT imaging, and the relation between the coronoid process and the zygomatic arch was evaluated with axial and coronal slices obtained from CBCT.

\section{CONCLUSION}

Plain radiographies can be used to detect $\mathrm{CH}$, but they can be insufficient in some cases in detecting $\mathrm{CH}$ and in evaluating the relation between the coronoid process and the zygomatic arch. When plain radiographies are not sufficient for diagnosis and evaluation of the $\mathrm{CH}$, CBCT can be used. 


\section{REFERENCES}

1. White SC, Pharoah MJ. Oral Radiology: Principles and Interpretation. $6^{\text {th }}$ ed. St Louis, The CV Mosby (Printed in China), Elsevier; 2009. p.484-5

2. McLoughlin PM, Hopper C, Bowley NB. Hyperplasia of the mandibular coronoid process: An analysis of 31 cases and a review of the literature. J Oral Maxillofac Surg 1995;53:250-5.

3. Halicioglu K, Celikoglu M, Buyuk SK, Sekerci AE, Ucar FI, Yavuz I. Three-dimensional evaluation of the mandibular third molars' development in unilateral crossbite patients: A cone beam computed tomography study. Eur J Dent 2014;8:389-94.

4. Karatas $\mathrm{OH}$, Toy E. Three-dimensional imaging techniques: A literature review. Eur J Dent 2014;8:132-40.

5. Colquhoun A, Cathro I, Kumara R, Ferguson MM, Doyle TC. Bilateral coronoid hyperplasia in two brothers. Dentomaxillofac Radiol 2002;31:142-6

6. Azaz B, Zeltser R, Nitzan DW. Pathoses of coronoid process as a cause of mouth-opening restrictions. Oral Surg Oral Med Oral Pathol 1994;77:579-84.

7. Leonardi R, Sorge G, Caltabino M. Bilateral hyperplasia of the mandibular coronoid processes associated with the nevoid basal cell carcinoma syndrome in an Italian boy. Br Dent J 2001;190:349-50.

8. Kubota Y, Takenoshita Y, Takamori K, Kanamoto M, Shirasuna K. Levandoski panographic analysis in the diagnosis of hyperplasia of the coronoid process. Br J Oral Maxillofac Surg 1999;37:409-11.

9. Mulder $\mathrm{CH}$, Kalaykova SI, Gortzak RA. Coronoid process hyperplasia: A systematic review of the literature from 1995. Int J Oral Maxillofac Surg 2012;41:1483-9.

10. Mavili E, Akyürek M, Kayikçioglu A. Endoscopically assisted removal of unilateral coronoid process hyperplasia. Ann Plast Surg 1999;42:211-6.
11. Galiè M, Consorti G, Tieghi R, Denes SA, Fainardi E, Schmid JL, et al. Early surgical treatment in unilateral coronoid hyperplasia and facial asymmetry. J Craniofac Surg 2010;21:129-33.

12. Tavassol F, Spalthoff S, Essig H, Bredt M, Gellrich NC, Kokemüller $\mathrm{H}$. Elongated coronoid process: CT-based quantitative analysis of the coronoid process and review of literature. Int J Oral Maxillofac Surg 2012;41:331-8.

13. Iqbal S, Hamid AL, Purmal K. Unilateral coronoid hyperplasia following trauma: A case report. Dent Traumatol 2009;25:626-30.

14. Ilguy M, Kursoglu P, Ilguy D. Three cases of elongated mandibular coronoid process with different presentations. Iran J Radiol 2014;11:e4031.

15. Zhong SC, Xu ZJ, Zhang ZG, Zheng YH, Li TX, Su K. Bilateral coronoid hyperplasia (Jacob disease on right and elongation on left): Report of a case and literature review. Oral Surg Oral Med Oral Pathol Oral Radiol Endod 2009;107:e64-7.

16. Pregarz M, Fugazzola C, Consolo U, Andreis IA, Beltramello A, Gotte P. Computed tomography and magnetic resonance imaging in the management of coronoid process hyperplasia: Review of five cases. Dentomaxillofac Radiol 1998;27:215-20.

\begin{tabular}{|l|l|}
\hline \multicolumn{2}{|c|}{ Access this article online } \\
\hline Quick Response Code: & Website: \\
& www.eurjent.com \\
& \\
&
\end{tabular}

